\title{
Technological Development, Clinical Application, Quality Assurance and Dosimetric Validation of Volumetric Modulated Arc Therapy (VMAT): A Comprehensive Literature Review
}

\author{
Chandi Prasad Bhatt ${ }^{1 *}$, Irfan Ahmad ${ }^{1}$, Manoj Kumar Semwal' ${ }^{2}$ Kundan Singh Chufal ${ }^{3}$ \\ ${ }^{1}$ Deptt of Radiotherapy, Batra Hospital \& Medical Research Centre, 1 Tughlakabad Institutional Area, New Delhi, India \\ ${ }^{2}$ Deptt of Radiotherapy, Army Hospital Research and Referral, Delhi Cantonment, New Delhi, India \\ ${ }^{3}$ Deptt of Radiotherapy, Rajiv Gandhi Cancer Institute \& Research Centre, Rohini, New Delhi, India
}

\begin{abstract}
Volumetric Modulated Arc Therapy (VMAT) is a recently developed technology which, similar to Intensity Modulated Radiotherapy (IMRT), utilizes optimization algorithms to find an acceptable solution. VMAT optimization algorithms are more complex and resource intensive than IMRT algorithms, as the former have to account for many more variables including machine-specific limitations. VMAT is distinguished from traditional fixed-beam IMRT in that radiation is delivered while the gantry rotates around the patient. It is a significant advancement over fixed gantry angle IMRT in terms of the efficiency of delivery of desired complex dose distributions (dose painting) in modern-day radiotherapy. The purpose of this review is to discuss the technological development, clinical applications and quality assurance of VMAT.
\end{abstract}

Keywords: Volumetric modulated arc therapy (VMAT); Quality assurance (QA); Intensity modulated arc therapy (IMAT); Intensity modulated radiotherapy (IMRT)

\section{Introduction}

External Beam Radiotherapy Therapy (EBRT) is a form of radiotherapy in which the tumour/target volume within a patient is irradiated with a radiation source placed at a distance from the patient. Initially, with 2-dimensional EBRT, two or more radiation beams of rectangular/square shape from different directions were directed towards a tumour resulting in the irradiation of considerable normal tissues within the treated volume. With the advent of imaging modalities such as CT, tumour delineation in 3 dimensions became possible and subsequently linear accelerators (Linacs) with MultiLeaf Collimators (MLC) were used to conform the radiation beam shape to the tumour/target from various beam directions leading to three-dimensional conformal radiation therapy (3DCRT). Intensity Modulated RadioTherapy (IMRT) was the next step in the evolution of conventional 3DCRT technology. With IMRT, in addition to geometrically conforming the beam to the target volume, modulation of the intensity/fluence of radiation across each broad beam resulted in significant improvement in conforming the treatment dose envelope to the target volume and sparing of the surrounding normal tissues. The broad beam was divided into beamlets/pencil beams for the purpose of intensity modulation and consequently, due to multiple subfields within a defined field, treatment delivery time was prolonged. VMAT is advancement over IMRT (fixed beam) wherein dose is delivered while the linac gantry rotates around the patient in an arc leading to reduced treatment delivery time. The purpose of this review is to summarize the literature on the technical aspects of VMAT development, implementation, quality assurance and dosimetric validation.

\section{Materials and Methods}

A search was performed on MEDLINE and Pubmed Central (PMC) with the search terms "Volumetric Modulated Arc Therapy", "VMAT", "Intensity Modulated Radiotherapy", "IMRT", "Dosimetry", "Dosimetric comparsion", "Optimization algorithm", "Quality Assurance", "Intensity Modulated Arc Therapy", "IMAT", "RapidArc", "SmartArc", "Tomotherapy", "Helical Tomotherapy", "Stereotactic Body
Radiotherapy", "SBRT”, "Progressive Resolution Optimization", "PRO”, "Electronic Portal Imaging Device", "EPID”, "iMatrixx", and their combinations. Additional articles were retrieved from the bibliographies of selected articles and citation information from SCOPUS. The article search was frozen on 1st October 2017 and subsequently articles were selected for inclusion in this review. The criteria for inclusion were English language publication, relevance and comprehensiveness of results. Finally the selected articles were categorized into three sections: Technological development of VMAT, clinical application of VMAT and, quality assurance and dosimetric validation of VMAT.

\section{Technological Development in VMAT}

In 1995 Cedric X Yu first introduced the concept of Intensity Modulated Arc Therapy (IMAT) [1]. Yu proposed photon treatment delivery in a rotational cone beam manner, where the modulation consists of different field shapes and dose weightings along a $270^{\circ}$ rotation. The radiation field conforms to the target using the MLC which changes its shape during gantry rotation. Also, two-dimensional beam intensity distributions at different beam angles are delivered with multiple superimposing arcs. A typical IMAT treatment plan proposed by Yu was delivered in 20 minutes or less with the technology available at that time, which was not significantly longer than conventional complex IMRT treatments. Other limitations were the unavailability of a reliable dose calculation engine for IMAT, restrictions on MLC movement as the gantry moved from one beam angle to the next and the inability to

*Corresponding author: Chandi Prasad Bhatt, Deptt of Radiotherapy, Batra Hospital \& Medical Research Centre, 1 Tughlakabad Institutional Area, New Delhi, India, Tel: 0091-9999214465; Fax: 0091-11-2995 6255; E-mail: cpbhatt.phy@ gmail.com

Received March 05, 2018; Accepted March 12, 2018; Published March 16, 2018

Citation: Bhatt CP, Ahmad I, Semwal MK, Chufal KS (2018) Technological Development, Clinical Application, Quality Assurance and Dosimetric Validation of Volumetric Modulated Arc Therapy (VMAT): A Comprehensive Literature Review. J Nucl Med Radiat Ther S9: 003. doi:10.4172/2155-9619.S9- 003

Copyright: $\odot 2018$ Bhatt CP, et al. This is an open-access article distributed under the terms of the Creative Commons Attribution License, which permits unrestricted use, distribution, and reproduction in any medium, provided the original author and source are credited. 
Citation: Bhatt CP, Ahmad I, Semwal MK, Chufal KS (2018) Technological Development, Clinical Application, Quality Assurance and Dosimetric Validation of Volumetric Modulated Arc Therapy (VMAT): A Comprehensive Literature Review. J Nucl Med Radiat Ther S9: 003. doi: 10.4172/2155-9619.S9-003

Page 2 of 11

change the MLC shape with less than $5^{\circ}$ gantry angle rotation. However, the main advantage of IMAT technique was significantly better dose conformity compared to conventional 3DCRT treatment.

After a long gap of six years, Ma et al in 2001 performed a dosimetirc study on optimised IMAT for prostate cancer [2]. With this technique, sub arc beam-weighting optimisation using a gradient search method was applied to generate concave-shaped isodose distributions for prostate radiation therapy and compared with IMRT. The authors concluded that the the two planning techniques were dosimetrically comparable. A drawback to the IMAT plans was the dose uniformity within the prostate was less than that of the IMRT plans.

Cedric X et al in 2001 at the University of Maryland School of Medicine performed a phase I clinical trial, in which 50 patients were treated using IMAT plans generated via forwarding planning technique [3]. In this study, two to five arcs were used and the average treatment time was $7.5 \mathrm{~min}$. This trial demonstrated that IMAT could be delivered safely and efficiently on a general-purpose linear accelerator. However, the trial could not be successfully implemented for routine clinical purpose due to the unavailability of an IMAT inverse planning system.

Multiple investigators proposed and successfully demonstrated IMAT treatment planning using a forward planning strategy [2-5]. The main limitations of all these studies was the calculation of complex IMAT treatment plans and the accuracy of MLC leaf sequencing.

Earl et al in 2003, performed a study which described an inverse treatment planning algorithm, called 'Direct Aperture Optimisation' (DAO) [6]. DAO was used to generate inverse treatment plans for IMAT with the key feature being that the MLC leaf positions and beam weights were the parameters which were optimised, as opposed to pencil beam weights. By using this technique, all of the delivery constraints (physical limitation of MLC, limitations of leaf motion speed and gantry rotation speed) were enforced during the software optimisation, thereby eliminating the need for a separate leaf-sequencing step. Removing the leaf-sequencing step significantly simplified the generation of inversely optimised IMAT treatment plans. In their IMAT planning process, prior to optimization the user defined the number and angular range of the arcs along with the prescription parameters. Subsequently, the software calculated the dose for each beam for the patient-specific CT data, performed the optimization with dose calculations and provided the results of analysis and delivery. Although DAO simplified the IMAT optimisation process, the restrictive nature of IMAT delivery constraints negatively impacted the ability of this technique to converge rapidly to an optimal solution. The need for a large number of iterations and slow cooling of the annealing algorithm lead to increased optimisation time, which increased the overall IMAT planning time.

Another IMAT clinical study was conducted at Ghent University Hospital, Belgium by Duthoy et al in 2004 [7]. In this study aperture shapes were first planned based on the beam's eye view (BEV) of the target and the critical structures, similar to the approach adopted by the University of Maryland [3]. However, the anatomy-based apertures were further refined by allowing the leaves to move slightly using a greedy search optimisation scheme [7]. Based on this technique, treatment planning studies on rectal cancer and whole abdominopelvic radiation therapywere also investigated $[7,8]$. The main limitation of this technique was longer treatment delivery time as compared to 3DCRT treatment.

Cameron C in 2005 developed a Sweeping Window Arc Therapy (SWAT) technique to deliver an IMRT treatment in one arc rotation [9]. SWAT is a variation of IMRT with DAO, that was initialized with a leaf sequence of sweeping windows that change position back and forth periodically to the target as the gantry rotates. The shapes of the MLC apertures before optimisation were initialised so that the MLC leaf positions sweep across the PTV as the gantry rotates around the patient. Optimisation of MLC leaf positions was then performed by simulated annealing and arc weight optimisation, which could be carried out at a constant or a variable angular dose rate.

Wong et al in 2002, proposed a new approach termed 'simplified IMAT' in which they used a forward planning approach for IMAT planning [5]. Simplified IMAT started with designing multiple arcs based on the BEV of the anatomy. Each arc served a well-defined planning goal such as covering the whole target or protecting a critical structure. The first arc conformed the MLC to the planning target volume (PTV) throughout the arc with the goal of generating a dose distribution as uniform as possible within the target volume. The weightings of the arc was subsequently optimised, assuming a constant dose rate delivery. The next step utilized one arc per critical organ where the MLCs were reconfigured, so that the beam aperture conformed to the PTV whie also excluding one critical organ throughout the arc. These sets of arcs shielding different vital organs would deliver a minimal dose to each critical organ but sacrificed dose uniformity within the target volume. The simplified IMAT strategy was applied clinically to various sites, including prostate and high-risk endometrial cancer $[10,11]$.

Shepard et al in early 2007 proposed a new approach to IMAT treatment planning called arc sequencing [12]. This method approximated each arc as a series of static beams. First, an optimized IMRT plan was produced and the resulting intensity map was recalculated with each arc approximated as a series of static beams separated by 10 degrees. Each static beam was then split into five beams each, separated by 2 degrees. Thus, the arc-sequencing algorithm converted an IMRT intensity map into a set of deliverable arcs while also accounting for the constraints imposed by the nature of arc delivery. However, this technique was limited by its inability to modulate dose rate and gantry rotation speed during treatment delivery, thereby falling short of realizing the full potential of IMAT. In addition, splitting the arc into static beams also led to a loss of PTV coverage.

Ulrich et al developed an optimisation technique, in which the arc therapy plans were optimised for a single-arc delivery [13]. In this technique, the aperture shapes were optimised by a Tabu search optimisation algorithm, and a gradient search optimised the aperture weights. The algorithm demonstrated better treatment plans than their in-house IMRT optimisation technique and required a variable dose rate delivery with gantry rotation.

Luan et al developed an arc sequencing algorithm for converting continuous intensity maps, using a k-link shortest path algorithm into multiple arcs [14]. First, the optimised intensity patterns were segmented into intensity profiles that aligned with a particular MLC leaf pair. Then each intensity profile was segmented into $\mathrm{k}$ MLC leaf openings using a k-link shortest path algorithm. The leaf openings for all beam angles were subsequently connected to form 1D IMAT arcs under the maximum leaf motion constraint using shortest path algorithm. Finally, the 1D IMAT arcs were combined to form the IMAT treatment arcs of MLC apertures. The algorithm was tested for prostate, breast, head and neck, and lung cancers, and the authors concluded that the achieved plan quality rivalled helical tomotherapy plans.

Based on the method developed by Luan et al, Wang et al sequenced the intensity patterns optimised for 36 equispaced static beam angles into a single-arc delivery [15]. They used an in-house devloped 
Citation: Bhatt CP, Ahmad I, Semwal MK, Chufal KS (2018) Technological Development, Clinical Application, Quality Assurance and Dosimetric Validation of Volumetric Modulated Arc Therapy (VMAT): A Comprehensive Literature Review. J Nucl Med Radiat Ther S9: 003. doi: 10.4172/2155-9619.S9-003

Page 3 of 11

Monte Carlo (MC) superposition dose calculation algorithm for dose calculation, which had built-in beam-interpolation capability for dynamic arc dose calculation to mimic continuous arc delivery.

Bzdusek et al developed an efficient method for VMAT planning where a single arc $\left(360^{\circ}\right.$ or less) was delivered with continuous variation of MLC segments, dose rate (DR), and gantry speed [16]. Their algorithm optimised fluence maps based on static gantry angles that were evenly spaced at every $24^{\circ}$ within the user-defined arc length. With the initial spacing of the arc segments at $24^{\circ}$, the fluence maps were initialised to the target apertures and optimised using standard gradient-based fluence optimisation. The optimised intensity maps were then converted into MLC segments and were evenly distributed within the arc, resulting in a single-arc MLC sequence. The user-defined final gantry spacing reached (after conversion and arc sequencing) was normally $4^{\circ}$, and created 91 total control points for a $360^{\circ}$ arc. Compared to IMRT, this algorithm could achieve equivalent or better plan quality in prostate, head \& neck, brain, and lung cancer cases.

In a similar approach, Bedford also optimised intensity maps for uniformly spaced beams over one or more arcs [17]. Their inverse planning algorithm consisted of three stages: Fluence optimisation, segmentation, and direct aperture optimisation (DAO). They also introduced the concept of a control point group, to overcome the inability of a single control point to deliver intensity-modulated radiation to the patient on its own. Intensity maps were sequenced into MLC apertures which approximated the fluence profiles and direct aperture optimisation (DAO) was used to improve the solution. It also took into account the permissible range of leaf motion of the MLC.

Several dosimetric and clinical studies have investigated the implementation of IMAT during the last two decades, but IMAT could not be adopted by most users in routine clinical practice, due to the unavailability of a robust, accurate and fast planning optimization algorithm, which remained a primary challenge till 2008.

In 2008, Karl Otto developed a single-arc IMAT-algorithm called Volumetric Modulated Arc Therapy (VMAT) which combined the capability of varying the dose rate of the linear accelerator with the prior accumulated experience with IMAT [18]. The VMAT optimisation method employed an aperture-based method that incorporated MLC leaf position and MU weights as optimisation parameters. The cost function was based on dose-volume constraints with a relative priority and importance value assigned to each constraint. During optimisation, MLC leaf position or MU weights were constrained such that the aperture shape and MU values were physically achievable, while also maintaining the ability to deliver dose continuously with maximum possible gantry rotation speed and dose rate. Optimisation started with a small number of samples of the continuous source and MLC motion. Each iteration of the optimisation involved randomly selecting an available gantry sample, then changing either the MU weight or an MLC leaf position for that sample. If a proposed change did not violate a mechanical or efficiency constraint of the dose distribution, then the cost function was calculated. If the cost function reduced with optimisation, the change was accepted. Otherwise, it was rejected by the algorithm. As the optimisation progressed, a new sample was placed between the existing samples. The algorithm used a continuous beam angle sampling to optimise a number of apertures using direct aperture optimisation, where the aperture shapes and their corresponding weights were initially optimising for a set number of coarsely placed gantry angles without taking the aperture connectivity into consideration. The samples were continually added in the optimisation process until a desirable sampling frequency was reached. This study concluded that VMAT optimization resulted in an impressive reduction in treatment delivery time (1.5-3.0 minutes for 200 cGy fraction).

Subsequent to the publication of Otto's algorithm, large-scale clinical implementation of VMAT started when VarianTM adopted his algorithm and promoted it under the trade name, RapidArcTM, in 2008. The linac control was updated to allow dose rate variation during gantry rotation. Subsequenly, ElektaTM introduced their IMAT solution with the trade name VMATTM (proprietary algorithm) and PhilipsTM Medical Systems introduced a rotational IMRT solution with the trade name SmartArcTM, based on the algorithm by Bzdusek et al [16].

Based on Otto's algorithm, Cozzi et al performed a treatment planning study with volumetric modulation of single arc radiotherapy plan on cervix uteri cancer patients [19]. The study utilised the Progressive Resolution Optimization (PRO) algorithm, in which the entire $360^{\circ}$ arc was initially optimised considering ten beam angles. Subsequently, the progress was then divided into major phases called multi-resolution (MR) levels and within each level, MLC shape, dose rate and gantry speed were simultaneously optimised. At the end of each MR level, the number of control points increased by a factor of two, and the progress repeated until the final number of 177 control points was reached. Ling et al and O'Daniel et al experimentally verified the delivery accuracy of RapidArc compared to TPS calculation estimation $[20,21]$.

Subsequent research focussed on assessing the significance of some specific features; the usage of collimator rotation, dose rate variation and MLC leaf speed [22]; the impact of couch modeling on treatment accuracy of RapidArcTM [23]; and a patient-specific quality assurance method for VMAT treatment delivery to enhance its planning, delivery and quality [24]. These features were incorporated into the newer versions of the PRO algorithm, named PRO2 and PRO3 and overcame the limitations of the original version, PRO $[23,24]$. These newer algorithms were further investigated by Nicolini et al [25]. In contrast to $\mathrm{PRO} 2$, all 178 control points (CPs) are generated at the first phase in $\mathrm{PRO} 3$ and are optimised during all phases of the algorithm. The dose calculation remains progressive and is calculated in sectors, from a coarse (about $18^{\circ}$ ) to a very fine resolution (about $2^{\circ}$ ) regarding the angles between adjacent calculations according to the four phases. In contrast to PRO2, PRO3 models the complex trajectories between CPs during early optimization phases, resulting in a faster convergence process. PRO3 also includes jaw tracking (for additional OAR sparing) and the ability to perform intermediate dose calculations (for improving the agreement between optimisation and final calculation phases) thereby improving the final VMAT planning results.

\section{Clinical Application of VMAT}

The general concepts and processes for VMAT planning are not very different from IMRT planning, with the basic inverse planning principles being almost identical. In contrast to IMRT planning, VMAT planning also permits simultaneous variation of gantry rotation speed, MLC leaf position and dose rate, thus resulting in higher number of degrees of freedom to achieve an optimal solution. However, the number of beams used to approximate an arc and the need for maintaining aperture connectivity between them, combined with more degrees of freedom make VMAT planning computationally challenging. Despite its many dosimetric and clinical advantages, the difficulties in VMAT treatment planning have been the biggest obstacle in its clinical implementation. 
Citation: Bhatt CP, Ahmad I, Semwal MK, Chufal KS (2018) Technological Development, Clinical Application, Quality Assurance and Dosimetric Validation of Volumetric Modulated Arc Therapy (VMAT): A Comprehensive Literature Review. J Nucl Med Radiat TherS9: 003.doi: 10.4172/2155-9619.S9-003

Page 4 of 11

After the introduction of the concept of IMAT by Cedric X Yu in 1995 [1], their group at the University of Maryland clinically implemented the technique and reported the results of a phase I clinical trial for 50 patients with cancers of the central nervous system, head and neck, and prostate, from November 1999 to May 2001 [3] The study concluded that IMAT achieved highly conformal dose distribution for different treatment sites. However, the clinical implementation of IMAT at this time used complex forward planning and hence it was not practically possible to utilise the IMAT for routine clinical purposes. The authors concluded that inverse treatment planning systems were required for the purpose.

Based on the optimisation principle developed by Karl Otto [18], Cozzi et al reported the first treatment planning study on RapidArc (VMAT), which compared plan quality with fixed field IMRT [19]. VMAT Treatment plans for eight patients with cancer of cervix uteri were generated using PRO algorithm and compared to 5-field dynamic IMRT plans. The study concluded that in comparsion to IMRT, significant improvements in OAR and healthy tissue sparing could be achieved with VMAT without compromising target coverage. The authors suggested that the potential benefits of improved physical dose distribution when combined with a shorter delivery time could result in improved daily treatment quality and increased system throughput.

Wolff et al performed a comparative dosimetric analysis of VMAT with other available radiotherapy techniques (serial tomotherapy, stepand-shoot IMRT and 3DCRT) for the treatment of prostate cancer [26]. The study concluded that intensity-modulated techniques yield treatment plans of significantly improved quality when compared to 3D-conformal therapies, with serial tomotherapy providing best OAR sparing. VMAT emerged as the most efficient treatment option with a reduced treatment time of 1.8-3.7 min and less than $400 \mathrm{MU}$ recquired for the delivery of a $2 \mathrm{~Gy}$ fraction.

Fogliata et al performed a dosimetric study on the potential benefits and limitations of the RapidArc (RA) treatment concept compared to Helical Tomotherapy (HT) and fixed gantry intensity modulation techniques (IMRT), for 12 patients presenting with benign brain tumours [27]. The study concluded that all techniques resulted in equivalent target coverage as well as OAR sparing, and suggested further dosimetric studies be performed on complex sites to provide more clinjcal context.

Matuszak et al performed a treatment planning study with VMAT for four diverse clinical situations, stereotactic body radiosurgery (SBRT) of the lung, SBRT of the spine, pediatric cancer and bone marrow sparing whole-abdominopelvic irradiation (WAPI) [28]. The study identified SBRT, paediatric cases, and bone-marrow-sparing WAPI as three scenarios in which VMAT could have a positive impact on dosimetric plan quality and treatment delivery time. Spine and lung SBRT cases treated with VMAT had shorter treatment times, $(37 \%$ and 59\% reduction in treatment times for spine and lung, respectively) compared to alternative IMRT or conformal plans. The study concluded that VMAT planning improved dosimetric parameters and had the potential to significantly reduce treatment time, without sacrificing plan quality.

Nicolini et al investigated the newly developed PRO3 algorithm for different clinical sites (anal canal, brain metastases, lung and Head \& neck) and also explained the planning strategy for each site [25]. The results of the study showed that in comparision to PRO2, PRO3 improved plan quality and increased planning efficiency. PRO3 also increased the agreement between optimisation and final dose calculation phases and demonstarated a significant advantage in speed and technical aspects.

Several comparative clinical studies have been conducted with VMAT and other IMRT techniques after the commercial launch of VMAT in 2008 [29-36]. Most of the investigators concluded that VMAT planning achieved similar or better conformity, improved homogeneity within the PTV and similar or better sparing of OARs. All studies also found significant reductions in the number of MUs and treatment delivery time with VMAT.

Table 1 summarises the literature on comparisons of VMAT with other RT techniques. The techniques investigated include 3D-CRT, Static Beam IMRT, Dynamic Conformal Arc (DCA), Helical tomotherapy (HT), co-planar and non-coplanar IMRT, VMAT single Arc (SA) and VMAT Double Arc (DA), for different cancer sites and doses.

Most of these planning studies have reported improved or similar PTV coverage with VMAT techniques compared with fixed field IMRT [27-32]. The conclusion of different studies on target volume homogeneity and conformity are more conflicting; some studies reported improved conformity and homogeneity with VMAT $[29,32,33]$, while others reported better results with fixed field IMRT [31]. This variation could be due to some planning factors, as the number of arcs used in the VMAT plans, the type of VMAT optimisation approach (in general, double arc plans have better conformity and homogeneity compared with single arc methods), and the number of fields used in the fixed field IMRT plans.

The degree of OARs sparing depends mainly on the location of PTV and OARs. Most of the studies reported similar or better sparing of OARs [23,33-37], but some studies reported that IMRT had a better OARs sparing than VMAT $[32,38]$.

A unanimous finding from all planning studies quoted above is, the improved efficiency of VMAT delivery with a reduction in treatment delivery times and MU per fraction. A single arc VMAT treatment plan is likely to be delivered in 1-1.5 minute whereas a 5-7 field IMRT plan would normally require 5-10 minutes. Consequently, VMAT overcomes the issue of intra-fraction motion (and concerns regarding inadequate target volume coverage) due to rapid treatment delivery. Due to higher number of MU's and treatment time per fraction, the primary concerns with any IMRT technique is the increased risk of radiation-induced secondary malignancy. Though VMAT plans result in lower MU's and shorter treatment times, it is worth noting that the dose distribution typically obtained with VMAT plans show an increase in the low dose radiation volume in the body compared to IMRT (due to the spread of dose from the complete arc of $360^{\circ}$ ).

In recent years, there has also been increasing interest in utilizing VMAT for SBRT and SRS, with promising results [39]. Research on dosimetric and clinical validation of VMAT for SBRT, SRS/SRT, and FFF beams is ongoing. Recently a Phase II trial of hypofractionated VMAT-based treatment for early-stage breast cancer with VMAT was completed by De Rose et al [44]. The authors concluded that the 3-week VMAT-SIB course as adjuvant treatment after breast-conserving surgery showed to be well tolerated and was associated with optimal local control. Fogliata et al performed a similar study on moderately hypofractionated radiotherapy (HRT) with VMAT and simultaneous integrated (SIB) boost for pelvic irradiation in prostate cancer for 90 patients and concluded that HRT with VMAT and SIB on the whole pelvis in unfavourable prostate cancer patients is effective with a mild pattern of toxicity [45]. Navarria et al also reported on hypofractionated 
Citation: Bhatt CP, Ahmad I, Semwal MK, Chufal KS (2018) Technological Development, Clinical Application, Quality Assurance and Dosimetric Validation of Volumetric Modulated Arc Therapy (VMAT): A Comprehensive Literature Review. J Nucl Med Radiat Ther S9: 003.doi: 10.4172/2155-9619.S9-003

Page 5 of 11

\begin{tabular}{|c|c|c|c|c|c|c|c|}
\hline $\begin{array}{l}\text { Author, Year } \\
\text { of publication, } \\
\text { VMAT commercial } \\
\text { system }\end{array}$ & Plan Comparison & $\begin{array}{l}\text { Number of } \\
\text { patients }\end{array}$ & $\begin{array}{l}\text { Treatment Site and } \\
\text { Radiation dose }\end{array}$ & PTV & OAR & MU per fraction & $\begin{array}{l}\text { Treatment time per } \\
\text { fraction }\end{array}$ \\
\hline $\begin{array}{l}\text { Fogliata et al, } \\
\text { 2008, VMAT by } \\
\text { RapidArc [27] }\end{array}$ & $\begin{array}{l}\text { Non-Coplanar } \\
\text { IMRT (5-7F,SW) } \\
\text { vs VMAT vs HT }\end{array}$ & 12 & $\begin{array}{l}\text { Meningioma (60Gy/30 } \\
\text { Fx), acoustic neuroma } \\
(54 G y / 30 \mathrm{Fx}) \text {, pituitary } \\
\text { adenoma (50Gy/25 } \\
\text { Fx) }\end{array}$ & $\begin{array}{l}\text { Target coverage } \\
\text { equivalent among all } \\
\text { techniques. VMAT } \\
\text { and IMRT are slightly } \\
\text { better than HT for dose } \\
\text { conformity. }\end{array}$ & $\begin{array}{l}\text { OARs sparing of } \\
\text { VMAT and IMRT } \\
\text { was better than HT. } \\
\text { Lower integral dose } \\
\text { to body in VMAT } \\
\text { and IMRT compared } \\
\text { with HT. }\end{array}$ & NR & NR \\
\hline $\begin{array}{l}\text { Verbakel et al, } \\
\text { 2009, VMAT by } \\
\text { RapidArc [29] }\end{array}$ & $\begin{array}{l}\text { VMAT (SA) vs } \\
\text { VMAT -Double Arc } \\
\text { (DA) vs IMRT (7F, } \\
\text { SW) }\end{array}$ & 12 & $\begin{array}{l}\text { Nasopharynx, } \\
\text { oropharynx and } \\
\text { hypopharynx (70Gy/35 } \\
\text { Fx ) }\end{array}$ & $\begin{array}{l}\text { Similar PTV coverage. } \\
\text { Double Arc VMAT was } \\
\text { superior to SA VMAT } \\
\text { and IMRT for Dose } \\
\text { homogeneity. }\end{array}$ & $\begin{array}{l}\text { No significant } \\
\text { difference for OARs. } \\
\text { Dose to Parotid was } \\
\text { lower with DA VMAT } \\
\text { (by average 2Gy) } \\
\text { compared with SA } \\
\text { VMAT }\end{array}$ & $\begin{array}{l}\text { VMAT (SA), 439; } \\
\text { VMAT (DA), 459; } \\
\text { IMRT, } 1108\end{array}$ & NR \\
\hline $\begin{array}{l}\text { Vanetti et al, } \\
\text { 2009, VMAT by } \\
\text { RapidArc [30] }\end{array}$ & $\begin{array}{l}\text { VMAT (SA) vs } \\
\text { VMAT (DA) vs } \\
\text { IMRT (7-9F, SW) }\end{array}$ & 29 & $\begin{array}{l}\text { Oropharynx, } \\
\text { hypopharynx and } \\
\text { larynx }(66 \mathrm{~Gy} / 30 \mathrm{Fx}, \\
60 \mathrm{~Gy} / 30 \mathrm{Fx} \text { and } \\
54 \mathrm{~Gy} / 30 \mathrm{Fx})\end{array}$ & $\begin{array}{l}\text { Similar PTV coverage } \\
\text { and Conformity. DA } \\
\text { VMAT superior to SA } \\
\text { VMAT and IMRT for } \\
\text { homogeneity (SA VMAT } \\
\text { slightly inferior to IMRT) }\end{array}$ & $\begin{array}{l}\text { VMAT plan was } \\
\text { superior to IMRT for } \\
\text { sparing spinal cord } \\
\text { (D2\%), brainstem } \\
\text { (D2\%, mean dose) } \\
\text { and parotid glands } \\
\text { (mean dose). DA } \\
\text { VMAT better than SA } \\
\text { VMAT. VMAT - lower } \\
\text { integral doses to } \\
\text { body }\end{array}$ & $\begin{array}{l}\text { VMAT (SA), 463; } \\
\text { VMAT (DA), 584; } \\
\text { IMRT, } 1126\end{array}$ & $\begin{array}{l}\text { VMAT (SA): } \\
1.221 .5 \mathrm{~min} ; \\
\text { VMAT (DA): } \\
3 \text { min; } \\
\text { IMRT: } 15 \text { min }\end{array}$ \\
\hline $\begin{array}{l}\text { Guckenberger et } \\
\text { al, 2009, VMAT by } \\
\text { SmartArc [34] }\end{array}$ & $\begin{array}{l}\text { IMRT (9F,SS) vs } \\
\text { VMAT (1-3 arcs) }\end{array}$ & 20 & $\begin{array}{l}\text { Prostate, } \\
\text { Postoperative pharynx/ } \\
\text { larynx, primary } \\
\text { pharynx, paranasal } \\
\text { sinus } 66 \mathrm{~Gy} / 30 \mathrm{Fx} \text { and } \\
60 \mathrm{~Gy} / 30 \mathrm{Fx})\end{array}$ & $\begin{array}{l}\text { PTV coverage and } \\
\text { homogeneity results by } \\
\text { site are as follows: } \\
\text { - } \quad \text { Prostate - SA } \\
\text { VMAT superior to } \\
\text { IMRT } \\
\text { - Post-operative } \\
\text { pharynx/larynx/ } \\
\text { primary pharynx } \\
\text { - SA VMAT } \\
\text { was inferior to } \\
\text { IMRT, DA VMAT } \\
\text { was IMRT and } \\
\text { TA VMAT was } \\
\text { superior to IMRT } \\
\text { Paranasal sinus } \\
\text { - All VMAT plans } \\
\text { were inferior } \\
\text { to IMRT (due } \\
\text { to decreased } \\
\text { coverage between } \\
\text { orbits) }\end{array}$ & $\begin{array}{l}\text { OAR sparing results } \\
\text { by site are as follows: } \\
\text { - } \quad \text { Prostate - SA } \\
\text { VMAT superior } \\
\text { to IMRT } \\
\text { - } \text { Postoperative } \\
\text { pharynx/ } \\
\text { larynx, Primary } \\
\text { pharynx - No } \\
\text { significant } \\
\text { difference } \\
\text { between VMAT } \\
\text { and IMRT (SA } \\
\text { VMAT inferior } \\
\text { to DA VMAT; } \\
\text { TA VMAT and } \\
\text { IMRT). } \\
\text { Paranasal sinus } \\
\text { - All IMRT } \\
\text { plans superior } \\
\text { to VMAT for } \\
\text { lens-sparing }\end{array}$ & $\begin{array}{l}\text { VMAT (SA), 358- } \\
\text { 440; VMAT (DA), } \\
\text { 460-519; VMAT } \\
\text { (TA), 506-560, IMRT, } \\
\text { 430-688; }\end{array}$ & $\begin{array}{l}\text { IMRT, 9.55-12.25 } \\
\text { min; VMAT (SA), } \\
1.8522 \text { min; VMAT } \\
\text { (DA), 3.8323.98 } \\
\text { min; VMAT (TA), } \\
4.42-4.58 \text { min }\end{array}$ \\
\hline $\begin{array}{l}\text { Wagner et al, } \\
\text { 2009, VMAT by } \\
\text { RapidArc [37] }\end{array}$ & $\begin{array}{l}\text { 3D-CRT (2-8F) vs } \\
\text { IMRT }(5-9 F, S W) \\
\text { vs VMAT (SA) }\end{array}$ & 14 & $\begin{array}{l}\text { High-grade glioma } \\
\text { (60Gy) }\end{array}$ & $\begin{array}{l}\text { IMRT was superior to } \\
\text { VMAT and 3D-CRT for } \\
\text { PTV coverage. 3D-CRT } \\
\text { was equivalent to IMRT } \\
\text { and VMAT for coverage } \\
\text { of PTVs distant from } \\
\text { OAR but significantly } \\
\text { inferior for PTVs close } \\
\text { to OARs. VMAT was } \\
\text { slightly better than } \\
\text { IMRT for conformity. }\end{array}$ & $\begin{array}{l}\text { VMAT was slightly } \\
\text { better than IMRT and } \\
\text { 3D-CRT for OAR } \\
\text { sparing (chiasm, } \\
\text { brainstem). With } \\
\text { VMAT, normal brain } \\
\text { received highest } \\
\text { mean dose to and } \\
\text { highest } V_{5} \text { to healthy } \\
\text { tissue }\end{array}$ & $\begin{array}{l}\text { VMAT, 321.1; IMRT, } \\
\text { 587.8; CRT, } 224\end{array}$ & $\begin{array}{l}\text { VMAT was } 56 \mathrm{~s} \\
\text { faster than IMRT } \\
\text { and } \\
1.26 \text { min faster than } \\
\text { CRT. }\end{array}$ \\
\hline $\begin{array}{l}\text { Lagerwaard et al, } \\
\text { 2009, VMAT by } \\
\text { RapidArc [39] }\end{array}$ & $\begin{array}{l}\text { VMAT (SA) vs } \\
1 D C A \text { vs 5DCA }\end{array}$ & 3 & $\begin{array}{l}\text { Acoustic neuroma } \\
\text { (single radiosurgery } \\
12.5 \mathrm{~Gy} \text { ) }\end{array}$ & $\begin{array}{l}\text { Similar PTV coverage } \\
\text { for all techniques. } \\
\text { VMAT better than DCA } \\
\text { for conformity }\end{array}$ & $\begin{array}{l}\text { VMAT and 1DCA: } \\
\text { smaller volume of } \\
\text { the normal brain } \\
\text { receiving low } \\
\text { radiation dose } \\
\text { compared with 5DCA. } \\
\text { VMAT and 5DCA } \\
\text { - same maximum } \\
\text { doses for cochlea, } \\
\text { brain stem, trigeminal } \\
\text { nerve (1DCA gave } \\
\text { higher doses } \\
\text { compared with VMAT } \\
\text { and 5DCA). }\end{array}$ & $\begin{array}{l}\text { VMAT: } \\
\text { 2763-2869; } \\
\text { 5DCA: } \\
\text { 2483-2769 }\end{array}$ & $\begin{array}{l}\text { VMAT, } 4-5 \mathrm{~min} ; \\
5 \text { DCA, } 20-30 \mathrm{~min}\end{array}$ \\
\hline
\end{tabular}


Citation: Bhatt CP, Ahmad I, Semwal MK, Chufal KS (2018) Technological Development, Clinical Application, Quality Assurance and Dosimetric Validation of Volumetric Modulated Arc Therapy (VMAT): A Comprehensive Literature Review. J Nucl Med Radiat Ther S9: 003. doi: 10.4172/2155-9619.S9-003

Page 6 of 11

\begin{tabular}{|c|c|c|c|c|c|c|c|}
\hline $\begin{array}{l}\text { Bertelsen et al, } \\
\text { 2010, VMAT by } \\
\text { SmartArc [35] }\end{array}$ & $\begin{array}{l}\text { IMRT(5-7F, SS) vs } \\
\text { VMAT (SA) }\end{array}$ & 25 & $\begin{array}{l}\text { Oropharynx and } \\
\text { hypopharynx }(68 \mathrm{~Gy} / 33 \\
\mathrm{Fx} \text { and } 66 \mathrm{~Gy} / 33 \mathrm{Fx})\end{array}$ & $\begin{array}{l}\text { Equivalent or superior } \\
\text { target coverage } \\
\text { and conformity and } \\
\text { homogeneity with } \\
\text { VMAT. }\end{array}$ & $\begin{array}{l}\text { VMAT was superior } \\
\text { to IMRT at sparing } \\
\text { spinal cord, } \\
\text { parotid glands, } \\
\text { submandibular glands } \\
\text { at high dose levels. } \\
\text { With VMAT, lower } \\
\text { volumes of healthy } \\
\text { tissue (outside PTV) } \\
\text { irradiated to higher } \\
\text { doses }\end{array}$ & $\begin{array}{l}\text { VMAT: } 460 ; \\
\text { IMRT: } 503\end{array}$ & $\begin{array}{l}\text { VMAT: } 4.02 \mathrm{~min} \text {; } \\
\text { IMRT: } 6.2 \mathrm{~min}\end{array}$ \\
\hline $\begin{array}{l}\text { McGrath et al, } \\
\text { 2010, VMAT by } \\
\text { SmartArc [40] }\end{array}$ & $\begin{array}{l}\text { 3D-CRT (7-10 } \\
\text { Non-coplanar) } \\
\text { vs VMAT (single } \\
\text { partial arc) }\end{array}$ & 21 & $\begin{array}{l}\text { Stage IA NSCLC } \\
\text { SBRT } 48 \mathrm{~Gy} \text { in } 12 \mathrm{Fx}\end{array}$ & $\begin{array}{l}\text { VMAT was superior } \\
\text { to 3D-CRT for } \\
\text { conformity at } 80 \% \\
\text { and } 50 \% \text { isodose } \\
\text { levels. No difference in } \\
\text { homogeneity }\end{array}$ & $\begin{array}{l}\text { Significant dose } \\
\text { reduction in } \\
\text { lung volume }\left(\mathrm{V}_{20} / \mathrm{V}_{12.5} /\right. \\
\left.\mathrm{V}_{10} / \mathrm{V}_{5}\right) \text { with VMAT. No } \\
\text { significant difference } \\
\text { in mean dose to other } \\
\text { OAR's. }\end{array}$ & $\begin{array}{l}\text { 3D-CRT, 2235, } \\
\text { VMAT, 2360; }\end{array}$ & $\begin{array}{l}\text { 3D-CRT 7.2-14.9 } \\
\text { min, } \\
\text { VMAT: 5.1-8.0 min; }\end{array}$ \\
\hline $\begin{array}{l}\text { Ong et al, } \\
\text { 2010, VMAT by } \\
\text { RapidArc [32] }\end{array}$ & $\begin{array}{l}\text { 3D-CRT non- } \\
\text { coplanar (10F) } \\
\text { Vs DCA vs IMRT } \\
\text { (9-10F coplanar), } \\
\text { SW vs VMAT (DA) }\end{array}$ & 18 & $\begin{array}{l}\text { Peripheral Lung } \\
\text { tumours Stagel: } \\
\text { treated with SBRT } \\
54 \mathrm{~Gy} / 3 \mathrm{Fx}, 55 \mathrm{~Gy} / 5 \mathrm{Fx} \text {, } \\
\text { and } 60 \mathrm{~Gy} / 8 \mathrm{Fx}\end{array}$ & $\begin{array}{l}\text { VMAT superior to } \\
\text { 3D-CRT, DCA and IMRT } \\
\text { for conformity at } 80 \% \\
\text { and } 60 \% \text { isodose levels }\end{array}$ & $\begin{array}{l}\text { With VMAT, higher } \\
\text { lung doses }\left(\mathrm{V}_{20}, \mathrm{~V}_{5}\right) \\
\text { compared to } 3 \mathrm{D}-\mathrm{CRT} \\
\text { (no significant } \\
\text { difference with IMRT). } \\
\text { Also, VMAT was } \\
\text { better at sparing } \\
\text { chest wall }\left(\mathrm{V}_{45}, \mathrm{~V}_{30} \text {, }\right. \\
\left.\mathrm{V}_{20}\right) \text { compared to } \\
\text { 3D-CRT, DCA, and } \\
\text { IMRT }\end{array}$ & $\begin{array}{l}\text { VMAT, 1800-4320; } \\
\text { 3D- CRT, 1343- } \\
\text { 3222; } \\
\text { DCA, 1402-3364; } \\
\text { IMRT, 3338-8010 }\end{array}$ & $\begin{array}{l}\text { VMAT, } \\
\text { 3.9-10.5 min; } \\
\text { 3D-CRT, } 11.6 \mathrm{~min} ; \\
\text { IMRT, } 12 \text { min }\end{array}$ \\
\hline $\begin{array}{l}\text { Scorsetti et al, } \\
\text { 2010, VMAT by } \\
\text { RapidArc [36] }\end{array}$ & $\begin{array}{l}\text { IMRT (9F,SW) vs } \\
\text { VMAT (DA) }\end{array}$ & 6 & Mesothelioma (54Gy) & $\begin{array}{l}\text { Comparable PTV } \\
\text { coverage and } \\
\text { homogeneity. }\end{array}$ & $\begin{array}{l}\text { VMAT superior to } \\
\text { IMRT with respect } \\
\text { to sparing of some } \\
\text { OAR's (contralateral } \\
\text { lung } V_{20}, \text { kidney } D_{1 \%} \text {, } \\
\text { heart mean dose, } \\
\text { liver mean dose) }\end{array}$ & $\begin{array}{l}\text { IMRT: } 2195 \\
\text { VMAT: } 734 ;\end{array}$ & $\begin{array}{l}\text { IMRT: } 13.4 \mathrm{~min} \text {, } \\
\text { VMAT: } 3.7 \mathrm{~min} ;\end{array}$ \\
\hline $\begin{array}{l}\text { Ma et al, 2010, } \\
\text { VMAT by } \\
\text { RapidArc [38] }\end{array}$ & $\begin{array}{l}\text { IMRT }(7 F, S S) \text { vs } \\
\text { VMAT (SA) vs } \\
\text { VMAT (DA) }\end{array}$ & 10 & $\begin{array}{l}2-4 \text { brain } \\
\text { metastases } \\
(50 G y / 10 F x)\end{array}$ & $\begin{array}{l}\text { Similar PTV coverage. } \\
\text { DA VMAT slightly better } \\
\text { than SA VMAT and } \\
\text { IMRT for conformity and } \\
\text { homogeneity }\end{array}$ & $\begin{array}{l}\text { VMAT DA was better } \\
\text { than IMRT at sparing } \\
\text { brainstem, optic } \\
\text { nerves, lenses (lower } \\
\text { maximum doses). } \\
\text { With VMAT, higher } \\
\mathrm{V}_{5} \text { to healthy tissue, } \\
\text { but lower } \mathrm{V}_{15} \text { and } \mathrm{V}_{20} \\
\text { compared with IMRT }\end{array}$ & $\begin{array}{l}\text { VMAT (SA), 1199; } \\
\text { VMAT (DA), 1387; } \\
\text { IMRT, } 1944\end{array}$ & $\begin{array}{l}\text { Beam on time) } \\
\text { VMAT (SA), } 1.25 \\
\text { min; VMAT (DA), } \\
2.5 \text { min; IMRT, } 6.5 \\
\text { min; }\end{array}$ \\
\hline $\begin{array}{l}\text { Eppinga et al, } \\
\text { 2010, VMAT by } \\
\text { RapidArc [33] }\end{array}$ & $\begin{array}{l}\text { VMAT (DA) vs } \\
\text { IMRT }(5 F, S W)\end{array}$ & 10 & $\begin{array}{l}\text { Pancreas }(50.4 \mathrm{~Gy} / 28 \\
\text { Fx) }\end{array}$ & $\begin{array}{l}\text { Similar PTV coverage in } \\
\text { both types of planning. } \\
\text { VMAT superior to IMRT } \\
\text { for dose conformity }\end{array}$ & $\begin{array}{l}\text { Dose to kidneys, } \\
\text { liver, stomach, bowel, } \\
\text { and duodenum was } \\
\text { modestly reduced } \\
\text { with VMAT in } \\
\text { comparsion to IMRT. }\end{array}$ & $\begin{array}{l}\text { IMRT, 800; VMAT, } \\
561\end{array}$ & $\begin{array}{l}\text { (Beam-on time) } \\
\text { VMAT, less than } 3 \\
\text { min; IMRT, } 8 \text { min }\end{array}$ \\
\hline $\begin{array}{l}\text { Johnston et al, } \\
\text { 2011, VMAT by } \\
\text { RapidArc [31] }\end{array}$ & $\begin{array}{l}\text { VMAT (DA) vs } \\
\text { IMRT }(9 F, S W)\end{array}$ & 10 & $\begin{array}{l}\text { oropharynx and } \\
\text { Nasopharynx } \\
\text { (70Gy/35Fx, 63Gy/35 } \\
\text { Fx , 56Gy/35 Fx ) }\end{array}$ & $\begin{array}{l}\text { Similar for PTV } \\
\text { coverage. SIB IMRT } \\
\text { slightly better than } \\
\text { SIB VMAT for dose } \\
\text { conformity and dose } \\
\text { homogeneity }\end{array}$ & $\begin{array}{l}\text { Contralateral parotid } \\
\text { sparing was improved } \\
\text { with VMAT. No } \\
\text { significant differences } \\
\text { in the spinal cord, } \\
\text { brainstem doses. } \\
\text { Parotid gland sparing }\end{array}$ & $\begin{array}{l}\text { VMAT, 529; } \\
\text { IMRT, } 1628\end{array}$ & NR \\
\hline $\begin{array}{l}\text { Richetti et al, } \\
\text { 2010, VMAT by } \\
\text { RapidArc [41] }\end{array}$ & $\begin{array}{l}\text { 3D-CRT (3F) } \\
\text { vs VMAT (SA) } \\
\text { (matched cohort } \\
\text { of } 20 \text { patients } \\
\text { treated with } \\
\text { 3D-CRT) }\end{array}$ & 25 & Rectum (44Gy/22 Fx) & $\begin{array}{l}\text { Similar PTV coverage. } \\
\text { VMAT was superior } \\
\text { to 3D-CRT for dose } \\
\text { conformity (with a } \\
\text { trend to improvement } \\
\text { inhomogeneity) }\end{array}$ & $\begin{array}{l}\text { No difference in } \\
\text { bladder sparing. } \\
\text { VMAT was superior } \\
\text { to 3D-CRT at sparing } \\
\text { of femoral heads and } \\
\text { bowel. Lower integral } \\
\text { mean dose to the } \\
\text { body with VMAT. }\end{array}$ & $\begin{array}{l}\text { VMAT, 276; } \\
\text { 3D-CRT, } 293\end{array}$ & $\begin{array}{l}\text { VMAT, } 2.05 \mathrm{~min} \text {; } \\
\text { 3D-CRT, } \\
\text { 3.42 min }\end{array}$ \\
\hline
\end{tabular}


Citation: Bhatt CP, Ahmad I, Semwal MK, Chufal KS (2018) Technological Development, Clinical Application, Quality Assurance and Dosimetric Validation of Volumetric Modulated Arc Therapy (VMAT): A Comprehensive Literature Review. J Nucl Med Radiat Ther S9: 003. doi: 10.4172/2155-9619.S9-003

Page 7 of 11

\begin{tabular}{|c|c|c|c|c|c|c|c|}
\hline $\begin{array}{l}\text { Uto et al, } \\
\text { 2016, VMAT by } \\
\text { RapidArc [42] }\end{array}$ & $\begin{array}{l}\text { DCAT, IMRT, } \\
\text { coVMAT, and } \\
\text { ncVMAT }\end{array}$ & 10 & $\begin{array}{l}\text { Craniopharyngioma } \\
\text { (Brain) }(52.2 \mathrm{~Gy} / 29 \mathrm{Fx})\end{array}$ & $\begin{array}{l}\text { The homogeneity of } \\
\text { coVMAT and ncVMAT } \\
\text { were significantly better } \\
\text { than DCAT }\end{array}$ & $\begin{array}{l}\text { NcVMAT significantly } \\
\text { reduced the dose } \\
\text { to the bilateral } \\
\text { hippocampus } \\
\text { compared to coVMAT } \\
\text { and DCAT }\end{array}$ & NR & NR \\
\hline $\begin{array}{l}\text { Pursley et al, } \\
\text { 2017, VMAT by } \\
\text { RapidArc [43] }\end{array}$ & $\begin{array}{l}\text { IMRT 7F, VMAT } \\
\text { (VMAT_F, } \\
\text { VMAT_A, } \\
\text { VMAT_P, } \\
\text { VMAT_N) }\end{array}$ & 24 & $\begin{array}{l}\text { Head and Neck } \\
\text { (ipsilateral neck } 14 \\
\text { and bilateral neck } 10) \\
(66 \mathrm{~Gy})\end{array}$ & $\begin{array}{l}\text { For ipsilateral neck } \\
\text { irradiation, techniques } \\
\text { VMAT_F and VMAT_A } \\
\text { produced plans with } \\
\text { significantly better } \\
\text { Cl compared to } \\
\text { IMRT. Bilateral neck } \\
\text { irradiation, technique } \\
\text { VMAT_A produced } \\
\text { plans with significantly } \\
\text { worse Cl compared to } \\
\text { IMRT. }\end{array}$ & $\begin{array}{l}\text { For ipsilateral neck } \\
\text { irradiation, technique } \\
\text { VMAT_F resulted } \\
\text { in a higher contra- } \\
\text { lateral parotid } \\
\text { mean dose than } \\
\text { IMRT. For bilateral } \\
\text { neck irradiation } \\
\text { VMAT techniques } \\
\text { generated plans with } \\
\text { comparable OAR } \\
\text { sparing compared to } \\
\text { IMRT plans. }\end{array}$ & $\begin{array}{l}\text { Ipsilateral: } \\
\text { VMAT_F,448; } \\
\text { VMAT_A; 421; } \\
\text { VMAT_P,407; } \\
\text { VMAT_N, 395; } \\
\text { IMRT; } 641 \\
\text { Bilateral: VMAT_F; } \\
521 ; \text { VMAT_A; 496; } \\
\text { VMAT_AP, 571; } \\
\text { IMRT, } 1623\end{array}$ & NR \\
\hline \multicolumn{8}{|c|}{$\begin{array}{l}\text { Abbreviations: SW, sliding window; SS, step-and-shoot; IMRT: Intensity-modulated radiotherapy; 3F, three field IMRT; } 5 F \text {, five field IMRT; 7F, seven field IMRT; 9F, nine } \\
\text { field IMRT; VMAT: volumetric-modulated arc therapy; SA: Single Arc; DA: Double Arc; TA: Triple arc; ; VMAT_F: VMAT full-arc technique; VMAT_A: VMAT avoidance sector } \\
\text { technique; VMAT_P: VMAT partial-arc technique; VMAT_N: VMAT narrow-arc technique; DCA: dynamic conformal arc radiotherapy; SIB: simultaneous integrated boost; } \\
\text { HT: Helical Tomotherapy; NR, Not Reported; NSCLC: non-small cell carcinoma of the lung; PTV: Planning target volume; GTV: Gross tumour volume; CTV: Clinical target } \\
\text { volume OAR: organs at risk; MU: monitor units; V30 Gy, volume receiving >30 Gy }\end{array}$} \\
\hline
\end{tabular}

Table 1: Dosimetric comparison of VMAT with other RT techniques.

stereotactic radiotherapy (HSRT) alone using volumetric modulated arc therapy for 102 patients with single, large brain metastases not fit for surgical resection. The study concluded that hypo-fractionated VMAT is a safe and feasible treatment, with excellent local control and limited toxicity [46].

\section{Quality Assurance and Dosimetric Validation of VMAT}

The complexity of VMAT planning mandates more rigorous commissioning of the processes for its planning and delivery as compared to 3DCRT and IMRT. The commissioning process involves careful measurement of all physical parameters required by the treatment planning system (e.g., MLC transmission), evaluation of the mechanical and radiation characteristics of the delivery system (e.g., MLC leaf positioning accuracy), and an end-to-end test of VMAT.

With the development of inverse planning algorithms and technological innovation in LINAC platforms, Otto explained a fully developed VMAT treatment planning and delivery platform ready for patient treatment [18]. After the availability of a fully developed commercial VMAT treatment platform, the main challenge prior to clinical implementation is its commissioning and the validation of patient-specific QA procedures

In 2008 when VMAT treatment was clinically implemented in three institutes, there was no documented protocol available for its commissioning. Ling et al performed and reported the first study on the commissioning and QA of VMAT [20]. The authors described a prototype protocol, which provided an important first step for medical physicists to ensure accurate, reliable and safe use of VMAT. The main highlights of their study was: (a) assessment of the accuracy of DMLC position during VMAT delivery; (b) evaluation of the ability of the linac to modulate dose rate and gantry speed during VMAT plan delivery, and; (c) evaluation of the ability to accurately vary MLC leaf speed during VMAT delivery. Radiographic film was used to evaluate the results of different radiation tests. The study concluded that successful implementation of all VMAT tests assured that the Varian medical system's LINAC (Clinac model) has the functional ability to deliver
RapidArc treatments accurately. From Picket fence test with moving gantry, it was concluded that the test is sensitive enough to detect errors of up to $0.5 \mathrm{~mm}$. At the time of its publication, there was a lack of practical commissioning experience with VMAT, and their protocol became the de facto standard for VMAT commissioning. However, the main limitation of the study was the use of radiochromic film which is relatively less radiosensitive. However, the same tests can also be performed with alternative methods, using EPID or linear array of diode detector [47-49].

Bedford and Warrington also reported on the commissioning of VMAT and described the development and implementation procedures for another commercial linear accelerator (Elekta PreciseBeam VMAT with MLC and Beam Modulator heads) [50]. The tests suggested for VMAT commissioning in their study were: (a) beam flatness and symmetry with gantry arcing and at a lesser dose rate than the standard; (b) MLC leaf calibration to ensure that the position and speed of the MLC leaves were correct to deliver the right dose; (c) sliding window dose delivered by a DMLC, and; (d) the rotational accuracy of VMAT delivery to ensure that the gantry position, leaf position, and cumulative dose were flawlessly synchronised (as failure to achieve synchronisation would lead to incorrect dose). A shortcoming of their study was that it suggested the investigation of limited parameters like dose rate and did not test all parameters, as suggested by Ling et al [20].

An extensive report by Kaurin et al reported on tests for all parameters of VMAT on Elekta LINAC [48]. The main highlights of their study were the MLC positional tests (including Picket Fence test for static and arcing gantry) and Picket Fence test with intentional errors. They also tested the different physical and dosimetric parameter of VMAT like Dose Rate, Gantry Speed, leaf speed, and backup jaw speed.

After the successful documentation of commissioning process of VMAT, Mynampati et al explored the application of AAPM TG 119 (used for evaluating the accuracy of IMRT planning and delivery system) for VMAT planning and delivery [51]. In the study two 
Citation: Bhatt CP, Ahmad I, Semwal MK, Chufal KS (2018) Technological Development, Clinical Application, Quality Assurance and Dosimetric Validation of Volumetric Modulated Arc Therapy (VMAT): A Comprehensive Literature Review. J Nucl Med Radiat Ther S9: 003. doi: 10.4172/2155-9619.S9-003

Page 8 of 11

treatment plans were generated with 7-9 field dMLC IMRT and 1-2 arc VMAT technique on the EclipseTM platform. Dose prescription and planning objectives were optimised in order to achieve the goals of TG 119. The two treatment plans were compared using conformity index (CI) and homogeneity index (HI) (D5-D95). The test cases used were that of prostate, head and neck, C-shape, and multi-target, and prescribed a dose of $75.6 \mathrm{~Gy}, 50.4 \mathrm{~Gy}, 50 \mathrm{~Gy}$ and $50 \mathrm{~Gy}$, respectively. The authors reported that IMRT and VMAT plan showed similar results for all four test cases. The authors also compared total number of monitor units (MU) needed for each plan, and the ratio of total number of MU of static IMRT and VMAT plans and concluded that to produce similar dose distribution for complex cases like test head-and-neck and C-shaped, IMRT needed almost double the number of MUs needed by VMAT plan.

Barnes et al developed a new VMAT method to specifically check the dose versus gantry angle with the complete range of allowed gantry speeds and dose rates [49]. The MatriXX 2D ion chamber array was used in the study for measurements and comparison between the measured results and the plan showed good agreement. The tests were also found to be sensitive to a miscalibration of nominal gantry speed that, if undetected, may have led to a suboptimal VMAT treatment delivery.

After successful documentation of commissioning of VMAT planning for most of the commercial LINAC vendors, the next challenge was to design and validate patient-specific quality assurance tests for VMAT. One such study was reported by Bedford et al [47]. The authors evaluated the Delta4 diode array phantom (Scandidos, Uppsala, Sweden) for IMRT and VMAT plan verification. In the study, the array phantom was tested for angular sensitivity by irradiating it from 36 different gantry angles, the response to various step andshoot segment doses and dose rates. The measurements of the array phantom were compared with an ionisation chamber and film, for two head and neck IMRT plans, two prostate (with pelvic nodes) IMRT plans, and two lung VMAT plans. The results of their study showed that the uniformity of angular response was more than $0.5 \%$ over the range of gantry angles. The uniformity of response of the phantom to different segment monitor units and dose rates was more than $0.5 \%$. The assessment of IMRT and VMAT plans showed that the phantom measured a dose within $2.5 \%$ of the ionization chamber and compared to film recorded a slightly larger region (range $-2 \%$ to $+7 \%$ ) agreeing with the planned dose to within $3 \%$ and $3 \mathrm{~mm}$. Subsquently, several investigators have tested and validated the VMAT patient-specific QA by using Delta4 phantom [52-54].

O'Daniel et al investigated an effective and efficient end-to-end patient-specific quality assurance (QA) protocol for VMAT [21]. In their study, patient-specific QA of 39 VMAT treatment plans was done for three sites, brain, spine, and prostate. The patient-specific QA was analysed via three methods: (a) ion chamber (one-dimensional absolute, $\mathrm{n}=39$ ); (b) film, and; (c) 2D ion chamber array (ICA, 2D absolute, coronal/sagittal, $\mathrm{n}=39$ ) measurements, which were crossvalidated with film and calendric ion chamber. The authors concluded that the ion chamber, film, and ICA results all agreed well with the calculated dose, although the ICA results were slightly degraded in the presence of high-dose gradients in VMAT plan. It concluded that the film and ICA results agreed well and one could use any one of the three methods for the pretreatment patient-specific QA of VMAT.

Several researchers have investigated pre-treatment plan verification QA of VMAT plan with other methods. Boggula et al used the 2D Detector array (MatriXX detector) for patient-specific VMAT
QA with different setups and concluded that the combination of MatriXX together with the multicube phantom is an alternative to film QA [55]. The authors reported that it was a fast and reliable method for pretreatment verification of arc therapy with excellent agreement between calculated and measured fluence.

Li et al performed a study on evaluation of the ArcCHECK QA system for IMRT and VMAT verification [56]. In their study, the ArcCHECK device was tested for short-term reproducibility, dose linearity, dose per pulse dependence, dose rate dependence, field size dependence, out of field dependence and directional dependence. Eight simple plans each using four beams of different field sizes alongwith IMRT and VMAT plans for various sites in 10 patients were measured by ArcCHECK. The phantom data was compared with ion chamber measurements and planned results. For all pretreatment patientspecific VMAT and IMRT QA, the pass rates exceeded 93\% and 95\% respectively and high reproducibility of these results was observed by the authors from week to week. Investigations by other authors have also concluded that the ArcCHECK dosimetry system provides satisfactory results despite the complexity of VMAT plans and can be used for routine pretreatment QA [54,57-59].

QA of both IMRT and VMAT treatment plans performed by the medical physics staff is a time-consuming process and places a significant strain on resources, namely machine time, plan preparation and analysis. To reduce the workload an alternative method was proposed by Agnew et al using treatment trajectory log files [60]. The authors analysed pre- and on-treatment trajectory log files and OCTAVIUS 4D phantom ionisation chamber array measurements, on Varian TrueBeam LINAC. The trajectory log files recorded for every treatment fraction for all plans over the entire course of treatment were analysed. Delivery accuracy was assessed in terms of gantry angle and leaf position precision with gamma analysis of $2 \mathrm{D}$ fluence and $3 \mathrm{D}$ dose distributions. The authors reported a strong correlation between pretreatment ionization chamber array gamma results and on-treatment trajectory $\log$ file gamma results. The accuracy of VMAT plan delivery assessed using pre-treatment trajectory log file fluence delivery and ionization chamber array measurements were strongly correlated with on-treatment trajectory log file fluence delivery. The method reported by the authors demonstrated the potential to reduce patient specific QA workload [61-67].

The main limitation of all tools available for VMAT QA is that the measurement results depend on the setup accuracy of the phantom, which is a time-consuming process. Amorphous silicon (a-Si) based electronic portal imaging device (EPID) is an integral part of a linac and besides being used for portal imaging, is also widely used for dosimetric purposes for pre-treatment IMRT verification. It permits considerable time sparing alongwith good setup accuracy [68-70]. Using the dosimetric capabilities of EPID, Nicolini et al developed an algorithm for portal dosimetry verification of RapidArc (VMAT) plan named as the GLAaS algorithm, which converted raw images acquired with the EPID into dose matrices at a depth of the maximum dose (Dmax) [64]. The RapidArc plans optimised for test patients were selected from various tumour sites (brain, head and neck, thorax, and pelvis) and dose calculated for comparison with GLAaS algorithm obtained from Eclipse TPS. Measured matrices at Dmax after being converted into dose through GLAaS, were compared to the corresponding computed doses and evaluation was performed via gamma index. Modulation Index (MI) was also calculated for both measured and calculated dose matrices for each field. The same algorithm was also tested for sub-arc 
Citation: Bhatt CP, Ahmad I, Semwal MK, Chufal KS (2018) Technological Development, Clinical Application, Quality Assurance and Dosimetric Validation of Volumetric Modulated Arc Therapy (VMAT): A Comprehensive Literature Review. J Nucl Med Radiat Ther S9: 003. doi: 10.4172/2155-9619.S9-003

Page 9 of 11

of $6^{\circ}$ and $12^{\circ}$. The results of portal dosimetry of VMAT via EPID were satisfactory.

EPID based patient-specific QA has many advantages over other phantom based QA such as efficient setup, reproducible delivery, and flexible analysis tools. Subsequently, many investigators have also validated EPID based patient-specific QA of VMAT [65-68]. Zwan et al performed a study of an EPID-based system for gantry-resolved MLC quality assurance for VMAT QA [69].

Schreibmann et al performed a study on patient-specific volumetric reconstruction of the dose delivered during VMAT treatment using the DMLC and treatment controller log (Dynalog) files [24].The accuracy of VMAT delivery was analysed for five prostate patients. For each patient clinical treatment was delivered and values recorded in the log files for the gantry angle, dose rate, and MLC leaf positions were transformed into a new DICOM-compliant plan using a custom-developed software system. The plan was imported into a treatment planning system, and the dose distribution was recreated on the original patient CT by simply recomputing the dose. Their results showed that log files could be directly used for dose reconstruction without resorting to phantom measurements or setups.

The commissioning of VMAT should start with comprehensively testing for the accurate operation of the linac (AAPM Task Group 142) and different tests suggested by Ling et al [20]. Also, verification of the VMAT plan as per AAPM Task Group Report 119 [51] should follow the recommendation of Smith et al [70], for routine performance tests on day to day basis.

Many commercial systems have been tested and validated individually for a patient-specific test of IMRT and VMAT plan verification, using gamma index analysis. To cross-check the results of five available commercial QA systems (PTW 2D-Array, SunNuclear ArcCHECK, Scandidos Delta4, Varian EPID, and Gafchromic EBT2 film), Hussein et al investigated the variability of global gamma index $(\gamma)$ analysis of all the five QA systems for IMRT and VMAT QA [54]. A known error was introduced into the VMAT treatment plan to evaluate the variability of the gamma index analysis of all five commercial QA systems. The results reported by the authors concluded that the detector array configuration and resolution have a more significant impact on the experimental estimation of $\gamma$ due to under-sampling of the dose distribution, noise, blurring effects, or a combination.

Kumar et al reported on a multi-institution dosimetric study on analysis of patient-specific quality assurance in IMRT [71]. Pretreatment dose verifications at nine centres were performed by measuring the point dose using ionisation chamber in a slab phantom. The QA analysis of results of the IMRT pre-treatment dose verification QA divulged the presence of systematic errors in the chain of IMRT treatment process at a few centres included in the study. The author recommended that a dosimetry quality audit before commissioning of IMRT may play a critical role in avoiding such discrepancies. Many studies had been carried out to compare and validate IMRT planning, but very few large multi-institutional studies have been performed for VMAT. Fogliata et al conducted a multicenter (five centres) QA analysis to assess the reliability of RapidArc plan delivery and dosimetric performance using EPID based VMAT plan QA and portal dosimetry software [72]. More multi-institutional studies need to be performed for clinical validation of VMAT treatment technique with a different combination of dosimetry system and linac vendors.

Huang et al reported on the effect of small number MU/segment on the precision of VMAT delivery with various dose rates [73]. In the study, without re-optimising, the daily dose of the plans was deliberately decreased to 1.5 Gy and 1.0 Gy and delivered to a MatriXX 2D-array detectors to investigate how the changes in dose rate and daily doses impact the delivery accuracy. The study concluded that when using a VMAT plan prescribed to a small daily dose the use of a very high dose rate should be done with caution.

Swinnen et al tested the influence of the jaw tracking technique on the dose calculation accuracy of small field VMAT plans (stereotactic) using the Octavius 4D system and compared the result with EBT3 film [74]. The study concluded that using the MLC with high positional precision to shape the smallest apertures in contrast to jaw tracking was presently the most accurate treatment technique.

VMAT is a sophisticated technology due to simultaneous modulation of many physical parameters and use of the higher degree of freedom (control points) as compared to IMRT. The complexity of VMAT further increases with the complexity of target and treatment modality (SBRT \& SRS/SRT). Therefore, a comprehensive test of the delivery system (linac) is a pre-requisite at the time of commissioning, as recommended by most of the investigators. In addition, a pretreatment patient-specific QA is also a requirement for the VMAT delivery system.

\section{Summary}

VMAT is a novel radiotherapy treatment technique with distinct clinical advantages over 3DCRT and IMRT in most of cases. It has superior dosimetric parameters (conformity and homogeneity) over 3DCRT and IMRT, with better OAR sparing. Technological development of VMAT, its clinical application and quality assurance of VMAT have been critically reviewed with comparison with othe radiotherapy treatment technique as 3DCRT and IMRT and future research should focus on expanding its applications in more diverse clinical situations.

\section{Reference}

1. Yu CX (1995) Intensity-modulated arc therapy with dynamic multilea collimation: An alternative to tomotherapy. Phys Med Biol 40: 1435-1449.

2. Ma L, Yu CX, Earl M, Holmes T, Sarfaraz M, et al. (2001) Optimized intensitymodulated arc therapy for prostate cancer treatment. Int J Cancer 96: 379-384.

3. Cedric XY, Li XA, Ma L, Chen D, Naqvi S, et al. (2002) Clinical implementation of intensity-modulated arc therapy. Int J Radiat Oncol Biol Phys 53: 453-463.

4. Ramsey CR, Spencer KM, Alhakeem R, Oliver AL (2001) Leaf position error during conformal dynamic arc and intensity modulated arc treatments. Med Phys 28: 67-72.

5. Wong E, Chen JZ, Greenland J (2002) Intensity-modulated arc therapy simplified. Int J Radiat Oncol Biol Phys 53: 222-235.

6. Earl M, Shepard D, Naqvi S, Li X, Yu C (2003) Inverse planning for intensitymodulated arc therapy using direct aperture optimization. Phys Med Biol 48 1075.

7. Duthoy W, De Gersem W, Vergote K, Boterberg T, Derie C, et al. (2004) Clinical implementation of intensity-modulated arc therapy (IMAT) for rectal cancer. Int J Radiat Oncol Biol Phys 60: 794-806.

8. Duthoy W, De Gersem W, Vergote K, Coghe M, Boterberg T, et al. (2003) Whole abdominopelvic radiotherapy (WAPRT) using intensity-modulated arc therapy (IMAT): First clinical experience. Int J Radiat Oncol Biol Phys 57: 1019-1032.

9. Cameron C (2005) Sweeping-window arc therapy: An implementation of rotational IMRT with automatic beam-weight calculation. Phys Med Biol 50: 4317.

10. Wong E, D'Souza DP, Chen JZ, Lock M, Rodrigues G, et al. (2005) Intensity modulated arc therapy for treatment of high-risk endometrial malignancies. Int J Radiat Oncol Biol Phys 61: 830-841.

11. Bauman G, Gete E, Chen J, Wong E (2004) Simplified intensity-modulated arc therapy for dose escalated prostate cancer radiotherapy. Med Dosim 29: 18-25

12. Shepard D, Cao D, Afghan M, Earl M (2007) An arc-sequencing algorithm for intensity modulated arc therapy. Med Phys 34: 464-470. 
Citation: Bhatt CP, Ahmad I, Semwal MK, Chufal KS (2018) Technological Development, Clinical Application, Quality Assurance and Dosimetric Validation of Volumetric Modulated Arc Therapy (VMAT): A Comprehensive Literature Review. J Nucl Med Radiat Ther S9: 003. doi: 10.4172/2155-9619.S9-003

Page 10 of 11

13. Ulrich S, Nill S, Oelfke U (2007) Development of an optimization concept for arc-modulated cone beam therapy. Phys Med Biol 52: 4099-4119.

14. Luan S, Wang C, Cao D, Chen DZ, Shepard DM, et al. (2008) Leaf-sequencing for intensity-modulated arc therapy using graph algorithms. Med Phys 35: 61-69.

15. Wang C, Luan S, Tang G, Chen DZ, Earl MA, et al. (2008) Arc-modulated radiation therapy (AMRT): A single-arc form of intensity-modulated arc therapy. Phys Med Biol 53: 6291-6303.

16. Bzdusek K, Friberger H, Eriksson K, Hårdemark B, Robinson D, et al. (2009) Development and evaluation of an efficient approach to volumetric arc therapy planning. Med Phys 36: 2328-2339.

17. Bedford JL (2009) Treatment planning for volumetric modulated arc therapy. Med Phys 36: 5128-5138.

18. Otto K (2008) Volumetric modulated arc therapy: IMRT in a single gantry arc Med Phys 35: 310-317.

19. Cozzi L, Dinshaw KA, Shrivastava SK, Mahantshetty U, Engineer R, et al. (2008) A treatment planning study comparing volumetric arc modulation with RapidArc and fixed field IMRT for cervix uteri radiotherapy. Radiother Oncol 89: $180-191$

20. Ling CC, Zhang P, Archambault Y, Bocanek J, Tang G, et al. (2008) Commissioning and quality assurance of RapidArc radiotherapy delivery system. Int J Radiat Oncol Biol Phys 72: 575-581.

21. O'Daniel J, Das S, Wu QJ, Yin FF (2012) Volumetric-modulated arc therapy: Effective and efficient end-to-end patient-specific quality assurance. Int $J$ Radiat Oncol Biol Phys 82: 1567-1574.

22. Otto K (2009) Letter to the editor on 'Single-Arc IMRT? Phys Med Biol 54: L37-L41.

23. Vanetti E, Nicolini G, Clivio A, Fogliata A, Cozzi L (2009) The impact of treatment couch modelling on RapidArc. Phys Med Biol 54: N157-N166.

24. Schreibmann E, Dhabaan A, Elder E, Fox T (2009) Patient-specific quality assurance method for VMAT treatment delivery. Med Phys 36: 4530-4535.

25. Nicolini G, Clivio A, Cozzi L, Fogliata A, Vanetti E (2011) On the impact of dose rate variation upon RapidArc $₫$ implementation of volumetric modulated arc therapy. Med Phys 38: 264-271.

26. Wolff D, Stieler F, Welzel G, Lorenz F, Abo-Madyan Y, et al. (2009) Volumetric modulated arc therapy (VMAT) vs. serial tomotherapy, step-and-shoot IMRT and 3D-conformal RT for treatment of prostate cancer. Radiother Oncol 93: 226-233

27. Fogliata A, Clivio A, Nicolini G, Vanetti E, Cozzi L (2008) Intensity modulation with photons for benign intracranial tumours: A planning comparison of volumetric single arc, helical arc and fixed gantry techniques. Radiother Onco 89: $254-262$

28. Matuszak MM, Yan D, Grills I, Martinez A (2010) Clinical Applications of Volumetric Modulated Arc Therapy. Int J Radiat Oncol Biol Phys 77: 608-616.

29. Verbakel WF, Cuijpers JP, Hoffmans D, Bieker M, Slotman BJ, et al. (2009) Volumetric intensity-modulated arc therapy vs. conventional IMRT in head-andneck cancer: A comparative planning and dosimetric study. Int J Radiat Oncol Biol Phys 74: 252-259.

30. Vanetti E, Clivio A, Nicolini G, Fogliata A, Ghosh-Laskar S, et al. (2009) Volumetric modulated arc radiotherapy for carcinomas of the oro-pharynx hypo-pharynx and larynx: A treatment planning comparison with fixed field IMRT. Radiother Oncol 92: 111-117.

31. Johnston M, Clifford S, Bromley R, Back M, Oliver L, et al. (2011) Volumetricmodulated arc therapy in head and neck radiotherapy: A planning comparison using simultaneous integrated boost for nasopharynx and oropharynx carcinoma. Clin Oncol 23: 503-511.

32. Ong CL, Verbakel WF, Cuijpers JP, Slotman BJ, Lagerwaard FJ, et al. (2010) Stereotactic radiotherapy for peripheral lung tumors: a comparison of volumetric modulated arc therapy with 3 other delivery techniques. Radiother Oncol 97: 437-442

33. Eppinga W, Lagerwaard F, Verbakel W, Slotman B, Senan S (2010) Volumetric modulated arc therapy for advanced pancreatic cancer. Strahlenther Onkol 186: 382-387.

34. Guckenberger M, Richter A, Krieger T, Wilbert J, Baier K, et al (2009) Is a single arc sufficient in volumetric-modulated arc therapy (VMAT) for complex-shaped target volumes? Radiother Oncol 93: 259-265.

35. Bertelsen A, Hansen CR, Johansen J, Brink C (2010) Single arc volumetric modulated arc therapy of head and neck cancer. Radiother Oncol 95: 142-148.

36. Scorsetti M, Bignardi M, Clivio A, Cozzi L, Fogliata A, et al. (2010) Volumetric modulation arc radiotherapy compared with static gantry intensity-modulated radiotherapy for malignant pleural mesothelioma tumor: A feasibility study. Int $J$ Radiat Oncol Biol Phys 77: 942-949.

37. Wagner D, Christiansen $H$, Wolff $H$, Vorwerk $H$ (2009) Radiotherapy of malignant gliomas: Comparison of volumetric single arc technique (RapidArc), dynamic intensity-modulated technique and 3D conformal technique. Radiothe Oncol 93: 593-596.

38. Ma Y, Li M, Yin Y, Kong L, Sun X, et al. (2010) Hypofractionated stereotactic radiotherapy for brain metastases: $A$ dosimetric and treatment efficiency comparison between volumetric modulated arc therapy and intensity modulated radiotherapy. Technol Cancer Res Treat 9: 499-507.

39. Lagerwaard FJ, Meijer OW, Hoorn EA van der, Verbakel WF, Slotman BJ, et al. (2009) Volumetric modulated arc radiotherapy for vestibular schwannomas. Int J Radiat Oncol Biol Phys 74: 610-615.

40. McGrath SD, Matuszak MM, Yan D, Kestin LL, Martinez AA, et al. (2010) Volumetric modulated arc therapy for delivery of hypofractionated stereotactic lung radiotherapy: A dosimetric and treatment efficiency analysis. Radiother Oncol 95: 153-157

41. Richetti A, Fogliata A, Clivio A, Nicolini G, Pesce G, et al. (2010) Neo-adjuvan chemo-radiation of rectal cancer with volumetric modulated arc therapy: Summary of technical and dosimetric features and early clinical experience. Radiat Oncol 5: 14

42. Uto M, Mizowaki T, Ogura K, Hiraoka M (2016) Non-coplanar volumetric modulated arc therapy (VMAT) for craniopharyngiomas reduces radiation doses to the bilateral hippocampus: a planning study comparing dynamic conformal arc therapy, coplanar VMAT, and non-coplanar VMAT. Radiat Oncol 11: 86.

43. Pursley J, Damato AL, Czerminska MA, Margalit DN, Sher DJ, et al. (2017) A comparative study of standard intensity-modulated radiotherapy and RapidArc planning techniques for ipsilateral and bilateral head and neck irradiation. Med Dosim 42: 31-36

44. De Rose F, Fogliata A, Franceschini D, Navarria P, Villa E, et al. (2016) Phase II trial of hypofractionated VMAT-based treatment for early stage breast cancer: 2-year toxicity and clinical results. Radiat Oncol 11: 120.

45. Franzese C, Fogliata A, D’Agostino G, Di Brina L, Comito T, et al. (2017) Moderate hypofractionated radiotherapy with volumetric modulated arc therapy and simultaneous integrated boost for pelvic irradiation in prostate cancer. $J$ Cancer Res Clin Oncol 143: 1301-1309.

46. Navarria P, Pessina F, Cozzi L, Ascolese AM, De Rose F, et al. (2016) Hypofractionated stereotactic radiotherapy alone using volumetric modulated arc therapy for patients with single, large brain metastases unsuitable for surgical resection. Radiat Oncol 11: 76.

47. Bedford JL, Lee YK, Wai P, South CP, Warrington AP (2009) Evaluation of the Delta4 phantom for IMRT and VMAT verification. Phys Med Biol 54: N167-N176.

48. Kaurin DG, Sweeney LE, Marshall El, Mahendra S (2012) VMAT testing for an Elekta accelerator. J Appl Clin Med Phys 13: 3725

49. Barnes MP, Rowshanfarzad P, Greer PB (2016) VMAT linear accelerato commissioning and quality assurance: dose control and gantry speed tests. $J$ Appl Clin Med Phys 17: 246-261.

50. Bedford JL, Warrington AP (2009) Commissioning of volumetric modulated arc therapy (VMAT). Int J Radiat Oncol Biol Phys 73: 537-545.

51. Mynampati DK, Yaparpalvi R, Hong L, Kuo HC, Mah D (2012) Application of AAPM TG 119 to volumetric arc therapy (VMAT). J Appl Clin Med Phys 13 108-116

52. Korreman S, Medin J, Kjaer-Kristoffersen F (2009) Dosimetric verification of RapidArc treatment delivery. Acta Oncol 48: 185-191.

53. Feygelman V, Zhang G, Stevens C, Nelms BE (2011) Evaluation of a new VMAT QA device, or the "X" and "O" array geometries. J Appl Clin Med Phys 12: $146-168$

54. Hussein M, Rowshanfarzad P, Ebert MA, Nisbet A, Clark CH (2013) A 
Citation: Bhatt CP, Ahmad I, Semwal MK, Chufal KS (2018) Technological Development, Clinical Application, Quality Assurance and Dosimetric Validation of Volumetric Modulated Arc Therapy (VMAT): A Comprehensive Literature Review. J Nucl Med Radiat Ther S9: 003.doi: 10.4172/2155-9619.S9-003

comparison of the gamma index analysis in various commercial IMRT/VMAT QA systems. Radiother Oncol 109: 370-376

55. Boggula R, Birkner M, Lohr F, Steil V, Wenz F, et al. (2011) Evaluation of a 2D detector array for patient-specific VMAT QA with different setups. Phys Med Biol 56: 7163.

56. Li G, Zhang Y, Jiang X, Bai S, Peng G, et al. (2013) Evaluation of the ArcCHECK QA system for IMRT and VMAT verification. Phys Med 29: 295-303.

57. Neilson C, Klein M, Barnett R, Yartsev S (2013) Delivery quality assurance with ArcCHECK. Med Dosim 38: 77-80.

58. Chaswal V, Weldon M, Gupta N, Chakravarti A, Rong Y (2014) Commissioning and comprehensive evaluation of the ArcCHECK cylindrical diode array for VMAT pretreatment delivery QA. J Appl Clin Med Phys 15: 212-225.

59. Aristophanous M, Suh Y, Chi PC, Whittlesey LJ, LaNeave S, et al. (2016) Initial clinical experience with ArcCHECK for IMRT/VMAT QA. J Appl Clin Med Phys 17: $20-33$.

60. Agnew CE, Irvine DM, McGarry CK (2014) Correlation of phantom-based and log file patient-specific QA with complexity scores for VMAT. J Appl Clin Med Phys 15: 204-216.

61. Greer PB, Popescu CC (2003) Dosimetric properties of an amorphous silicon electronic portal imaging device for verification of dynamic intensity modulated radiation therapy. Med Phys 30: 1618-1627.

62. Van Esch A, Depuydt T, Huyskens DP (2004) The use of an aSi-based EPID for routine absolute dosimetric pre-treatment verification of dynamic IMRT fields. Radiother Oncol 71: 223-234.

63. Van Elmpt W, McDermott L, Nijsten S, Wendling M, Lambin P, et al. (2008) A literature review of electronic portal imaging for radiotherapy dosimetry. Radiother Oncol 88: 289-309.

64. Nicolini G, Vanetti E, Clivio A, Fogliata A, Korreman S, et al (2008) The GLAaS algorithm for portal dosimetry and quality assurance of RapidArc, an intensity modulated rotational therapy. Radiat Oncol 3: 24
65. Bakhtiari M, Kumaraswamy L, Bailey D, De Boer S, Malhotra H, et al (2011) Using an EPID for patient-specific VMAT quality assurance. Med Phys 38 1366-1373.

66. Adamson J, Wu Q (2012) Independent verification of gantry angle for pretreatment VMAT QA using EPID. Phys Med Biol 57: 6587-6600.

67. Liu B, Adamson J, Rodrigues A, Zhou F, Yin F, et al. (2013) A novel technique for VMAT QA with EPID in cine mode on a Varian TrueBeam linac. Phys Med Biol 58: 6683-6700.

68. Huang YC, Yeh CY, Yeh JH, Lo CJ, Tsai PF, et al (2013) Clinical practice and evaluation of electronic portal imaging device for VMAT quality assurance. Med Dosim 38: 35-41.

69. Zwan BJ, Barnes MP, Fuangrod T, Stanton CJ, O'Connor DJ, et al. (2016) An EPID-based system for gantry-resolved MLC quality assurance for VMAT. $J$ Appl Clin Med Phys 17: 348-365.

70. Smith K, Balter P, Duhon J, White GA, Vassy DL, et al. (2017) AAPM Medica Physics Practice Guideline 8. a.: Linear accelerator performance tests. J App Clin Med Phys 18: 23-39.

71. Kumar R, Sharma S, Deshpande S, Sresty NM, Bhatt CP, et al. (2014) Analysis of patient specific dosimetry quality assurance measurements in intensity modulated radiotherapy: A multi centre study. J Cancer Res Ther 10: 611-617.

72. Fogliata A, Clivio A, Fenoglietto P, Hrbacek J, Kloeck S, et al. (2011) Quality assurance of RapidArc in clinical practice using portal dosimetry. $\mathrm{Br} \mathrm{J}$ Radiol 84: $534-545$

73. Huang L, Zhuang T, Mastroianni A, Djemil T, Cui T, et al. (2016) Impact of small $\mathrm{MU} /$ segment and dose rate on delivery accuracy of volumetric-modulated arc therapy (VMAT). J Appl Clin Med Phys 17: 203-210.

74. Swinnen AC, Öllers MC, Roijen E, Nijsten SM, Verhaegen F (2017) Influence of the jaw tracking technique on the dose calculation accuracy of small field VMAT plans. J Appl Clin Med Phys 18: 186-195. 